\title{
ELECTRICAL AND MAGNETIC PROPERTIES
}

\section{Effect of Additions of Zinc Stearate on the Properties of Sintered Nd-Fe-B Magnets}

\author{
A. G. Popov ${ }^{a}$, E. G. Gerasimov ${ }^{a}$, P. B. Terent'ev ${ }^{a}$, V. S. Gaviko ${ }^{a}$, K. Yu. Shunyaev ${ }^{b}$ \\ T. L. Mikhailova ${ }^{b}$, V. O. Vas'kovskii ${ }^{c}$, and N. A. Kulesh ${ }^{c}$ \\ ${ }^{a}$ Institute of Metal Physics, Ural Branch, Russian Academy of Sciences, ul. S. Kovalevskoi 18, Ekaterinburg, 620990 Russia \\ ${ }^{b}$ Institute of Metallurgy, Ural Branch, Russian Academy of Sciences, ul. Amundsena 101, Ekaterinburg, 620016 Russia \\ ${ }^{c}$ Yeltsin Ural Federal University, ul. Mira 19, Ekaterinburg, 620002 Russia \\ e-mail:apopov@imp.uran.ru
}

Received July 2, 2012; in final form, October 3, 2012

\begin{abstract}
Zinc stearate additions have been used to increase the remanence of sintered $\mathrm{Nd}-\mathrm{Fe}-\mathrm{B}$ magnets produced by the powder metallurgy without powder pressing. Zinc stearate acts as an internal lubricant, i.e., it decreases the friction forces between the particles and favors an increase in the degree of texture of the powders, which is induced by the magnetic field. It is shown that the density and the magnetic hysteresis characteristics of sintered magnets produced using additions of $0.15 \mathrm{wt} \%$ zinc stearate exceeds the corresponding values obtained for magnets produced without this addition at a filling density of powders in containers of more than 2.9 and $3.0 \mathrm{~g} / \mathrm{cm}^{3}$ in dry and wet states, respectively. Using additions of zinc stearate in the amount of $0.15 \%$ with respect to the weight of the powder, magnets with a density of $7.55 \mathrm{~g} / \mathrm{cm}^{3}, B_{\mathrm{r}}=14.02 \mathrm{kG}, H_{\mathrm{c}}=7.91 \mathrm{kOe}$, and $(B H)_{\max }=46.1 \mathrm{MG}$ Oe have been produced.
\end{abstract}

Keywords: $\mathrm{Nd}-\mathrm{Fe}-\mathrm{B}$ alloys, sintered magnets, powder metallurgy method, pressless process (PLP), internal lubricants, zinc stearate

DOI: $10.1134 / \mathrm{S} 0031918 X 13040066$

\section{INTRODUCTION}

The latest advance in the field of producing sintered $\mathrm{Nd}-\mathrm{Fe}-\mathrm{B}$ permanent magnets has been related to the development of a new process suggested by Masato Sagava (Japan), which is characterized by the absence of the stage of pressing powders [1-3] (pressless process (PLP)). The powders are placed into special containers, are vibrationally compacted, textured in a pulsed magnetic field, and sintered directly in these containers. A significant advantage of the PLP is in the excluding of large and heavy press-electromagnets from the technological cycle, which facilitates the hermetization of the equipment employed for the production of magnets with a low concentration of oxygen (less than $0.2 \mathrm{wt} \%$ ).

In our previous work [4], we studied the effect of the average particle size $D_{\mathrm{av}}$, filling powder density $\rho_{\mathrm{f}}$, and conditions of powder texture on the density $\rho$ and magnetic hysteresis properties of sintered $\mathrm{Nd}-\mathrm{Fe}-\mathrm{B}$ magnets produced by the PLP using both traditional technology (TT) and low-oxygen technology (LOT). In the first case, powders ground in a vibration mill in a toluene medium were dried in air; in the second case, grinding was performed in a jet mill using nitrogen as the working gas. Subsequently, manipulations with powders were performed in glove boxes without contact with air oxygen. It has been shown that the values of $\rho_{\mathrm{f}}$ that provide for the optimum relationship between the density $\rho$ and the degree of texture in sintered magnets are 2.5-3.0 and $2.2 \mathrm{~g} / \mathrm{cm}^{3}$ for the TT and LOT, respectively. At smaller values of $\rho_{\mathrm{f}}$, the necessary density of magnets is not achieved after sintering; at higher $\rho_{\mathrm{f}}$, an insufficient level of texture and a low remanent induction $B_{\mathrm{r}}$ are formed.

The factor responsible for a decrease in the degree of texture with increasing $\rho_{\mathrm{f}}$ is an increase in friction forces between powder particles. In this work, to decrease the friction forces we used an internal lubricant (zinc stearate). Additions of zinc stearate have been used previously to increase the degree of texture in sintered magnets produced from $\mathrm{SmCo}_{5}$ and $\mathrm{Nd}-\mathrm{Fe}-\mathrm{B}$ alloys in traditional technologies using powder pressing $[5,6]$. Since, in these technologies the filling density of powders during texturing is not high (e.g., for $\mathrm{Nd}-$ $\mathrm{Fe}-\mathrm{B}$ it is $\sim 2.0 \mathrm{~g} / \mathrm{cm}^{3}$ ), the effect due to the additions of zinc stearate was insignificant. To both obtain a perfect shape of magnets and decrease the dimensions of containers, in PLP, it is preferable to use powders with $\rho_{\mathrm{f}} \geq 3.0 \mathrm{~g} / \mathrm{cm}^{3}$. Therefore, the importance of the problem of using internal lubricants in PLP increases substantially. 
Table 1. Zinc stearate concentrations used in experiments

\begin{tabular}{l|l|l|l|l|l|l|l|l}
\hline $\begin{array}{l}\text { Ratio of the masses of powders of zinc stearate and } \\
\text { Nd-Fe-B alloy, wt \% }\end{array}$ & 0 & 0.05 & 0.10 & 0.15 & 0.20 & 0.25 & 0.50 & 1.00 \\
\begin{tabular}{l} 
Concentration of zinc stearate in toluene, $\mathrm{mg} / \mathrm{mL}$ \\
\hline
\end{tabular} & 0 & 0.1719 & 0.3438 & 0.5156 & 0.6875 & 0.8594 & 1.7188 & 3.4375 \\
\hline
\end{tabular}

\section{EXPERIMENTAL}

In the experiments, we used a rapidly quenched stripcasting-type Fe-based alloy containing $31.5 \mathrm{wt} \% \mathrm{Nd}$ and $1 \mathrm{wt} \% \mathrm{~B}$. The alloy was embrittled using hydrogen treatment. After rough grinding, powders of the $\mathrm{Nd}-$ $\mathrm{Fe}-\mathrm{B}$ alloy were mixed with a powder of zinc stearate $\left(\mathrm{C}_{36} \mathrm{H}_{70} \mathrm{O}_{4} \mathrm{Zn}\right)$ taken in the proportions given in Table 1 , then milled together in a vibrating mill in a toluene medium. Since zinc stearate is well dissolved in toluene, an important parameter of the process of milling becomes the concentration of zinc stearate in toluene (see Table 1, line 2; the volume of toluene in each vessel of the mill was $64 \mathrm{~mL}$ ). By varying the milling time, powders were prepared with different average particle sizes $(2.55-3.24 \mu \mathrm{m})$, which were determined using the Fisher method. The shape and dimensions of the powder particles were observed in a QUANTA-200 scanning electron microscope. The concentration of zinc stearate on the surface of powder particles was determined based on the spectra obtained using a Nanohunter X-ray fluorescent spectrometer.

The wet or dried-in-air powders were charged into molybdenum containers with an internal cylindrical cavity $16 \mathrm{~mm}$ in diameter and $16 \mathrm{~mm}$ high. The filling density $\rho_{\mathrm{f}}$ of the powders charged varied from 2.5 to $3.5 \mathrm{~g} / \mathrm{cm}^{3}$. The texturing of the powders was performed in solenoids of a pulsed field, which was applied in the direction parallel to the axis of the cylindrical cavity of the container. The degree of texture induced by the magnetic field in the powders was estimated using the technique described in detail in [4]. In the descending segments of the hysteresis loops of the powders, which were measured in the closed circuit of the hysteresigraph in a field of $10 \mathrm{kOe}$, the value of the magnetization $4 \pi M$ was determined, which was denoted as $B_{10}$ and was used as the measure of the degree of texture. The powders were sintered directly in molybdenum containers. Since zinc stearate begins to melt at a temperature of about $110^{\circ} \mathrm{C}$, to eliminate it from the surface, we used the slow heating of the samples in a vacuum at a rate of $10 \mathrm{~K} / \mathrm{min}$. The sintering was completed by isothermal holding at $1090^{\circ} \mathrm{C}$ for $1 \mathrm{~h}$. After sintering, all samples were subjected to additional heat treatment by the following regime: $0.5 \mathrm{~h}$ at $T_{1}+0.5 \mathrm{~h}$ at $T_{2}\left(T_{1}=900^{\circ} \mathrm{C} ; T_{2}=550-650^{\circ} \mathrm{C}\right)$ and were quenched to room temperature. The demagnetizing curves of the sintered magnets were measured in a closed magnetic circuit using a Permagraph device. The relative error in the determination of the values of $B_{\mathrm{r}}$ and the coercive force $H_{\mathrm{c}}$ was $\pm 2 \%$. The X-ray diffraction investigations were performed using a
DRON-6 diffractometer in $\mathrm{Cr} K \alpha$ radiation. The oxygen content in the sintered samples was determined by the reduction method (with a relative error of $2 \%$ ) using an ELTRA-ONH 2000 gas analyzer.

\section{RESULTS AND DISCUSSION}

\section{Effect of Additions of Zinc Stearate on Texturing of $\mathrm{Nd}-\mathrm{Fe}-\mathrm{B}$ Powders}

A comparison of the degree of texture induced by a magnetic field in the powders that were produced with and without an addition of $0.15 \mathrm{wt} \%$ zinc stearate was performed by measuring $B_{10}$ [4]. Figures $1 \mathrm{a}-1 \mathrm{~d}$ display the $B_{10}$ dependence on the maximum strength $H_{\mathrm{m}}$ of the applied texturing field for dry powders with $\rho_{\mathrm{f}}=$ $2.5,2.7,2.9$, and $3.1 \mathrm{~g} / \mathrm{cm}^{3}$, respectively. The first point in these curves corresponds to powders textured in the electromagnet of the Permagraph device with $H_{\mathrm{m}}=14 \mathrm{kOe}$. The subsequent points were obtained after texturing the powders by single pulses of the magnetic field with the pulse duration of $6.5 \mathrm{~ms}$ and amplitude values of 30,46 , and $70 \mathrm{kOe}$. The last point in the curves is obtained as a result of the application of five pulses with $H_{\mathrm{m}}=71 \mathrm{kOe}$; the pulses were applied such that, in each even pulse, the direction of the field vector was changed to the opposite. The degree of texture increases with increasing $H_{\mathrm{m}}$, but decreases with increasing filling density of the powders; however, at all values of $\rho_{\mathrm{f}}$, the powders produced by the addition of zinc stearate have higher values of $B_{10}$ compared to powders that were milled without this addition. It can also be noted that the use of zinc stearate increases the values of $B_{10}$ more efficiently in powders with greater filling density, as well as in powders that were textured with the application of five pulses of alternating polarities. Thus, the use of the additions of zinc stearate favors the increase in the degree of texture of the powders.

\section{Estimation of Content of Zinc Stearate in Powders of $\mathrm{Nd}-\mathrm{Fe}-\mathrm{B}$ Alloy}

It was of interest to obtain information on the amount of zinc stearate that should be localized on the surface of the powder particles upon milling in order to provide lubrication. The method of the estimation consisted of determination of the $\mathrm{Zn}$ concentration in the powder of the $\mathrm{Nd}-\mathrm{Fe}-\mathrm{B}$ alloy, calculation of the content of zinc stearate in powder samples on the basis of the formula $\mathrm{C}_{36} \mathrm{H}_{70} \mathrm{O}_{4} \mathrm{Zn}$, and comparison of this content with the ratio between the components in the 

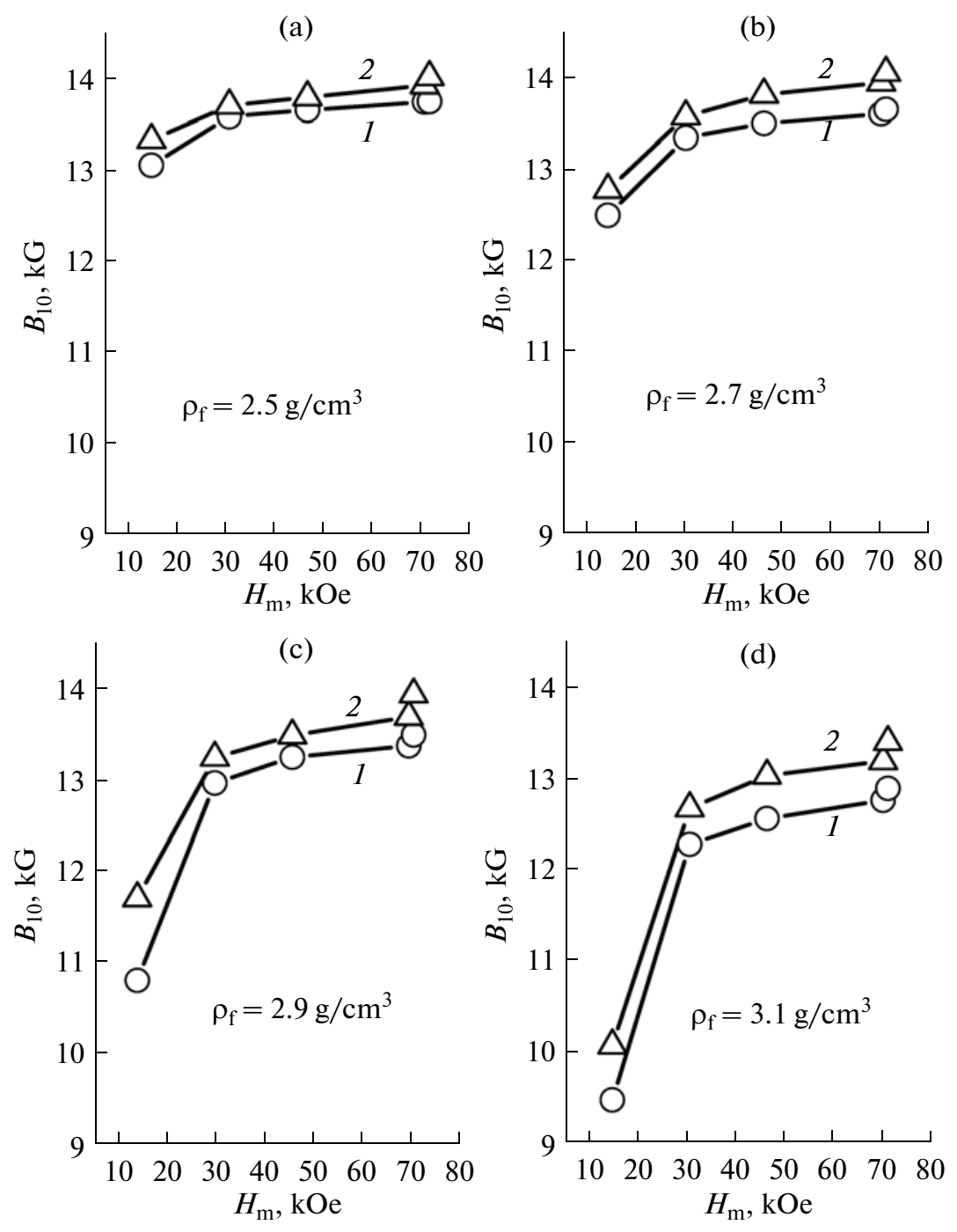

Fig. 1. Dependences of $B_{10}$ on maximum strength $H_{\mathrm{m}}$ of the applied texturing field for dry powders with (a) $\rho_{\mathrm{f}}=2.5$, (b) 27 , (c) 2.9 , and (d) $3.1 \mathrm{~g} / \mathrm{cm}^{3}$, which were prepared (1) without and (2) with the addition of $0.15 \mathrm{wt} \%$ zinc stearate.

initial mixture. Due to the obvious smallness of the concentration of $\mathrm{Zn}$ in the objects under investigation, a Rigaku Nanohunter precision analyzer of the elemental composition was used for its determination. The samples for the investigations were prepared by dissolving the powders in a $6 \%$ aqueous solution of nitric acid. Drops of these solutions were placed onto a microscope slide and dried to a state of thin homogeneous coatings, which were used to measure the spectra of the fluorescent radiation by the method of the total reflection of the primary X-ray beam.

Figure 2 displays these spectra for a powder without zinc stearate and for a sample produced from a powder with a $\mathrm{C}_{36} \mathrm{H}_{70} \mathrm{O}_{4} \mathrm{Zn}$ addition. It can be seen that, on a chosen scale, the spectra are nearly coincident and both contain clearly pronounced lines of the main components of the alloy, $\mathrm{Fe}$ and $\mathrm{Nd}$ (the light element $\mathrm{B}$ is not determined by the Nanohunter device); however, no lines of $\mathrm{Zn}$ are revealed. However, at a larger magnification, a $\mathrm{Zn}$ line is identified quite clearly, but only in the spectrum of the sample with an addition of zinc stearate (see inset in Fig. 2).

In view of the large difference in the intensities of the lines of the elements to be registered, samples of two types were used. The $\mathrm{Fe}$ and $\mathrm{Nd}$ contents were determined on two identical series of samples prepared from the low-concentration solutions of powders (to avoid the effects of the secondary fluorescent radiation), using the method of comparison with a reference powder of vanadium, which also was added to the solutions. It turned out that the ratio between $\mathrm{Fe}$ and $\mathrm{Nd}$ in all samples was almost the same, and equal to $85: 15$ (in at \%); the deviations did not exceed $0.1 \%$. These data and the results of their conversion with allowance for the presence of 6 at \% B in the powders are given in Table 2 . As can be seen, they differ only slightly from the results of standard chemical analysis, which also are given in Table 2. 


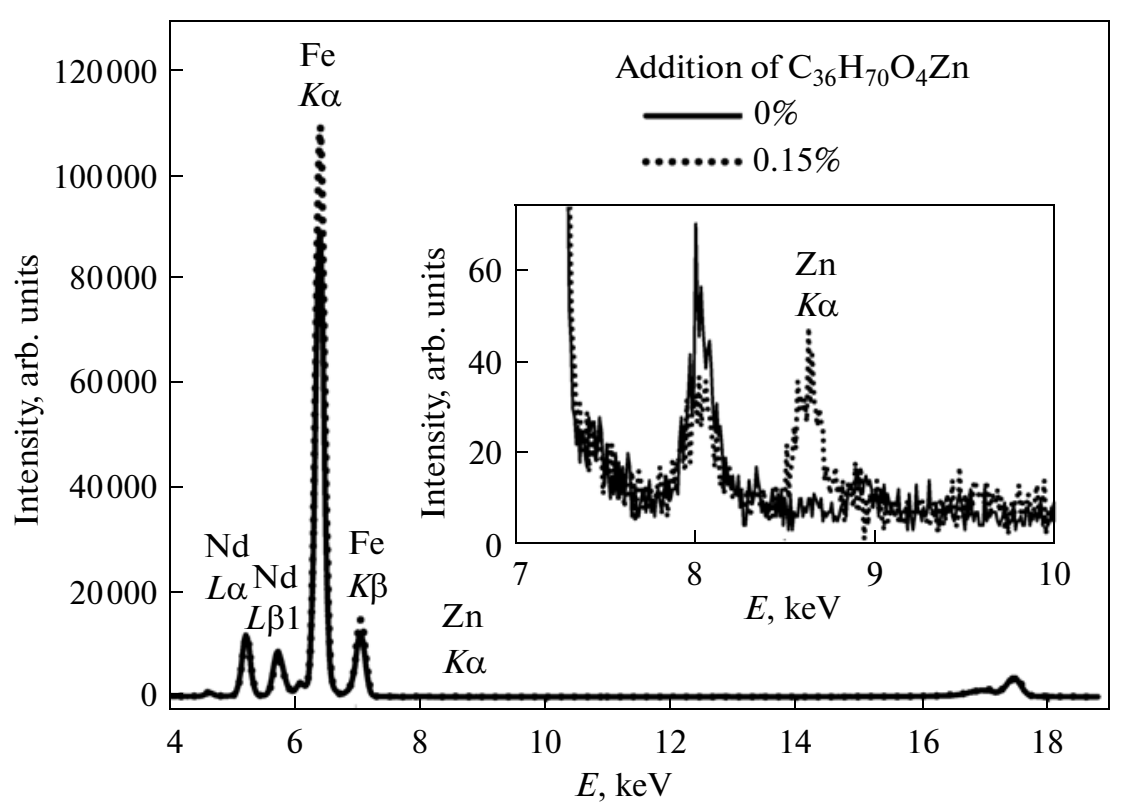

Fig. 2. Spectra of X-ray fluorescent radiation of initial powder (solid lines) of $\mathrm{Nd}-\mathrm{Fe}-\mathrm{B}$ alloy and powder produced by milling with an addition of $0.15 \mathrm{wt} \%$ zinc stearate (points). Inset shows fragments of spectra on greater scale.

To determine the small concentration of $\mathrm{Zn}$, we used samples prepared from high-concentrated powder solutions. In this case, we used the technique of comparing the intensities of the $\mathrm{Zn}$ line with the $\mathrm{Fe}$ and $\mathrm{Nd}$ lines in the regime of automated compensation of the background signal. It has been established that the $\mathrm{Zn}$ concentration is $0.011 \pm 0.001$ at $\%$ or, with allowance for the presence of boron in the samples, $0.010 \pm 0.001$ at $\%$ (Table 2). Since the zinc stearate molecule contains $10.44 \mathrm{wt} \% \mathrm{Zn}$, it follows from the data obtained that a significant fraction of $\mathrm{C}_{36} \mathrm{H}_{70} \mathrm{O}_{4} \mathrm{Zn}$ $(\sim 65 \%)$ dissolved in toluene $(0.015 \mathrm{wt} \%)$ is localized on the surfaces of powder particles.

\section{Effect of Zinc Stearate Concentration on Properties of Sintered $\mathrm{Nd}-\mathrm{Fe}-\mathrm{B}$ Magnets}

The sintered magnets were prepared from dry powders produced with additions of $0-1 \mathrm{wt} \%$ zinc stearate. The dependence of the properties of these magnets on the concentration of zinc stearate $C_{\mathrm{SZn}}$ is demonstrated in Table 3 . With increasing $C_{\mathrm{SZn}}$ up to $0.2 \mathrm{wt} \%$, the density of magnets $\rho$ increases slightly, whereas the remanence and the maximum energy product $(B H)_{\max }$ decrease. This dependence is explained by the fact that, as the zinc stearate concentration increases from 0 to $0.2 \mathrm{wt} \%$, the filling density of the powder loaded into the constant volume of the container under identical conditions of compacting increases. Although the average size of the powder grains determined by the Fisher method remains constant, the packing of the particles becomes more perfect, apparently, owing to a decrease in the friction forces. The increase in $\rho_{\mathrm{f}}$ is considered to be the main factor responsible for the gradual decrease in the degree of texture, despite the increasing amount of internal lubricant.

At $C_{\mathrm{SZn}}>0.2$ wt $\%$, all characteristics of the sintered magnets begin to decrease rather sharply. This is because of the increasing concentration of oxygen $C_{\mathrm{O}}$ in the magnets, which achieves $0.975 \mathrm{wt} \%$ at $C_{\mathrm{SZn}}=$

Table 2. Contents of the main chemical elements in the powders of the $\mathrm{Nd}-\mathrm{Fe}-\mathrm{B}$ alloy with an addition of zinc stearate

\begin{tabular}{c|c|c|c|c|l}
\hline $\begin{array}{c}\text { Units } \\
\text { of measurement }\end{array}$ & $\mathrm{Fe}$ & $\mathrm{Nd}$ & $\mathrm{Zn}$ & $\mathrm{B}$ & \multicolumn{1}{|c}{ Notes } \\
\hline at $\%$ & 85.0 & 15.0 & 0.011 & - & Nanohunter data \\
wt $\%$ & 68.6 & 31.4 & 0.010 & - & \\
at $\%$ & 80.0 & 14.0 & 0.010 & 6.0 & With allowance for 6 at \% boron \\
wt $\%$ & 68.0 & 31.1 & 0.010 & 0.9 & \\
at $\%$ & 79.54 & 14.37 & - & 6.09 & Alloy composition according to chemical analysis \\
wt $\%$ & 67.50 & 31.50 & - & 1.0 & \\
\hline
\end{tabular}


Table 3. Effect of concentration of zinc stearate on properties of sintered magnets. Properties were measured after additional annealing at $900^{\circ} \mathrm{C}$ for $0.5 \mathrm{~h}+600^{\circ} \mathrm{C}$ for $0.5 \mathrm{~h}$

\begin{tabular}{c|c|c|c|c|c|c|c}
\hline$C_{\mathrm{SZn}} \mathrm{wt} \%$ & $D_{\mathrm{av}}, \mu \mathrm{m}$ & $\rho_{\mathrm{f}}, \mathrm{g} / \mathrm{cm}^{3}$ & $\rho, \mathrm{g} / \mathrm{cm}^{3}$ & $B_{\mathrm{r}}, \mathrm{kG}$ & $H_{\mathrm{c}}, \mathrm{kOe}$ & $(B H)_{\max }, \mathrm{MG} \mathrm{Oe}$ & $C_{\mathrm{O}}, \mathrm{wt} \%$ \\
\hline 0 & 3.2 & 2.677 & 7.481 & 13.80 & 7.69 & 45.2 & 0.420 \\
0.05 & - & 2.870 & 7.518 & 13.69 & 8.06 & 43.6 & - \\
0.10 & 3.2 & 2.897 & 7.544 & 13.67 & 8.07 & 44.2 & 0.418 \\
0.15 & - & 2.920 & 7.530 & 13.62 & 8.23 & 43.6 & - \\
0.20 & - & 3.250 & 7.574 & 13.60 & 7.79 & 43.1 & - \\
0.25 & 3.2 & 3.029 & 7.399 & 13.52 & 4.08 & 28.4 & 0.447 \\
0.50 & 2.8 & 2.869 & 7.256 & 7.31 & 0.11 & 0.36 & 0.975 \\
1.00 & 2.6 & 2.877 & 7.148 & - & - & - & - \\
\hline
\end{tabular}

$0.5 \mathrm{wt} \%$. The increase in the oxygen concentration $C_{\mathrm{O}}$ is due to both the start of decreasing the size of the powder particles, which enhances the oxygen adsorption at the surface of the particles, and the introduction of additional oxygen with zinc stearate. Despite the measures that are undertaken to remove zinc stearate from the surface of the particles by a slow vacuum heating of the samples at $100-500^{\circ} \mathrm{C}$, the lubricant (introduced in a large amount) could not be removed entirely. This led to the appearance of numerous cracks in the sintered magnets obtained with the addition of more than $0.2 \mathrm{wt} \%$ zinc stearate, which, in particular, prevented measurements of the magnetic properties of the sample (Table 3, last line).

Additional proof that the introduction of zinc stearate is accompanied by an increase in the oxygen concentration in the magnets follows from the data of $\mathrm{X}$-ray diffraction analysis. Figure 3 displays the diffraction spectra of powders prepared from sintered magnets that were produced both without the addition

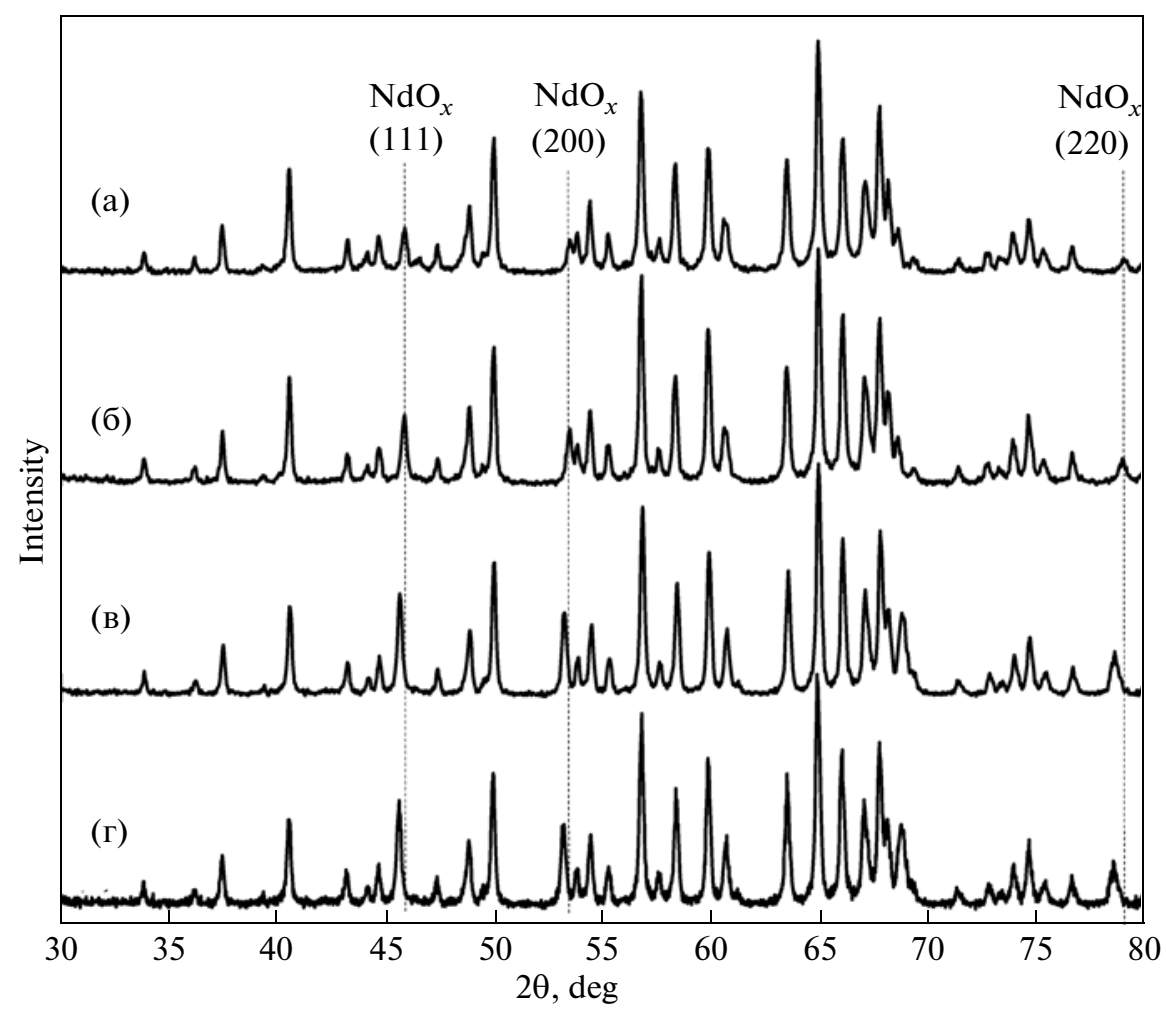

Fig. 3. X-ray diffraction patterns of powders prepared from sintered magnets produced (a) without and with the addition of zinc stearate in the amounts of (b) 0.1 , (c) 0.5 , and (d) $1.0 \mathrm{wt} \%$. 
Table 4. Phase composition and lattice parameters of phases present in sintered magnets

\begin{tabular}{|c|c|c|c|c|c|c|}
\hline \multirow{2}{*}{$C_{\mathrm{SZn}}$, wt $\%$} & \multirow{2}{*}{ Phase composition } & \multirow{2}{*}{$\begin{array}{l}\text { Volume fraction } \\
\text { of phases, } \%\end{array}$} & \multicolumn{4}{|c|}{ Lattice parameters } \\
\hline & & & $a, \AA$ & $c, \AA$ & $V,(\AA)^{3}$ & $c / a$ \\
\hline 0 & $\begin{array}{l}\mathrm{Nd}_{2} \mathrm{Fe}_{14} \mathrm{~B} \\
\mathrm{NdO} \\
\mathrm{Nd}_{2} \mathrm{O}_{3}\end{array}$ & $\begin{array}{l}* \\
2 \\
0.2 \\
\end{array}$ & $\begin{array}{l}8.804 \\
5.096 \\
3.839\end{array}$ & $\begin{array}{r}12.204 \\
5.998\end{array}$ & $\begin{array}{l}945.94 \\
132.34\end{array}$ & 1.386 \\
\hline 0.1 & $\begin{array}{l}\mathrm{Nd}_{2} \mathrm{Fe}_{14} \mathrm{~B} \\
\mathrm{NdO}\end{array}$ & $\begin{array}{c}* \\
2.5\end{array}$ & $\begin{array}{l}8.804 \\
5.098\end{array}$ & 12.203 & $\begin{array}{l}945.86 \\
132.50\end{array}$ & 1.386 \\
\hline 0.5 & $\begin{array}{l}\mathrm{Nd}_{2} \mathrm{Fe}_{14} \mathrm{~B} \\
\mathrm{NdO} \\
\mathrm{Nd}_{2} \mathrm{O}_{3}\end{array}$ & $\begin{array}{l}* \\
2.8 \\
0.14 \\
\end{array}$ & $\begin{array}{l}8.805 \\
5.120 \\
3.836\end{array}$ & $\begin{array}{r}12.187 \\
6.007\end{array}$ & $\begin{array}{l}944.83 \\
133.59\end{array}$ & 1.384 \\
\hline 1.0 & $\begin{array}{l}\mathrm{Nd}_{2} \mathrm{Fe}_{14} \mathrm{~B} \\
\mathrm{NdO} \\
\mathrm{Nd}_{2} \mathrm{O}_{3} \\
\mathrm{Fe}\end{array}$ & $\begin{array}{l}\text { * } \\
4.6 \\
0.04 \\
3.4\end{array}$ & $\begin{array}{l}8.805 \\
5.121 \\
3.768 \\
2.868\end{array}$ & $\begin{array}{r}12.188 \\
5.964\end{array}$ & $\begin{array}{l}944.91 \\
134.30\end{array}$ & 1.384 \\
\hline
\end{tabular}

Note: Phase analysis of sintered sample revealed the presence of an unidentified phase whose amount can be estimated as 5-10 vol $\%$. When calculating $\mathrm{X}$-ray diffraction patterns, this phase was taken into account together with the $\mathrm{Nd}_{2} \mathrm{Fe}_{14} \mathrm{~B}$ phase; therefore, the amount of the latter phase is not indicated precisely.

of zinc stearate and with additions of $0.1,0.5$, and $1.0 \mathrm{wt} \%$ zinc stearate. It can clearly be seen that there is an increase in the intensity of lines of the oxide $\mathrm{NdO}_{x}(x \sim 1)$ with increasing $C_{\mathrm{SZn}}$. Table 4 shows data on the amounts and lattice parameters of phases present in the magnets. At $C_{\mathrm{SZn}} \geq 0.5 \mathrm{wt} \%$, the lattice parameter $a$ of the oxide $\mathrm{NdO}_{x}$ with an fcc lattice becomes more than 5.11 $\AA$. However, this oxide, as was noted previously [7], is not capable of forming coherently bound defect-free interlayers at the grain boundaries of the $\mathrm{Nd}_{2} \mathrm{Fe}_{14} \mathrm{~B}$ alloy; thus, the coercive force $H_{\mathrm{c}}$ decreases sharply.

Thus, it has been established that, for this scheme of the experiment, the critical concentration of the introduced zinc stearate is $0.2 \mathrm{wt} \%$. At greater $C_{\mathrm{SZn}}$, the properties of the magnet decrease sharply; therefore, in subsequent experiments, we used the addition of zinc stearate in an amount of $0.15 \mathrm{wt} \%$.

\section{Comparison of the Effect of the Filling Density of Dry and Wet Powders on the Properties of Magnets}

The dependence of the properties of sintered magnets on the density of powders loaded into the containers is shown in Fig. 4. Qualitatively similar dependences were obtained for magnets prepared from both dry (Fig. 4a) and wet (Fig. 4b) powders with an average size of particles equal to $3.2 \mu \mathrm{m}$. The wet powders were used in order to decrease the amount of oxygen adsorbed at the surface of the particles. The values of $\rho, B_{\mathrm{r}}$, and $(B H)_{\max }$ of the magnets prepared from the powders without additions of zinc stearate exceed the corresponding values of these properties for the mag- nets with $C_{\mathrm{SZn}}=0.15 \mathrm{wt} \%$ at the filling densities less than 2.9 and $3.0 \mathrm{~g} / \mathrm{cm}^{3}$ in dry and wet states, respectively. At greater values of $\rho_{\mathrm{f}}$, the situation changes to the opposite, i.e., the values of $\rho, B_{\mathrm{r}}$, and $(B H)_{\max }$ of the magnets produced using the lubricant are prevalent, which is the main positive effect of using zinc stearate.

The coercive force of the magnets increases monotonically with increasing filling density. At the same time, the values of $H_{\mathrm{c}}$ of the magnets prepared from wet powders proved to be lower than the corresponding values of the magnets prepared from dry powders. This is due to two probable causes. The first cause is the rapid deterioration of the degree of texture with increasing $\rho_{\mathrm{f}}$ for dry powders and a known empirical regularity that consists in increasing $H_{\mathrm{c}}$ with an increase in the angle of misorientation of the easy axes of grains in $\mathrm{Nd}-\mathrm{Fe}-\mathrm{B}$ magnets [8]. The second cause, is the correlation between the low values of $\rho$ and $H_{c}$ of sintered magnets prepared from the powders with $\rho_{\mathrm{f}}<$ $2.9 \mathrm{~g} / \mathrm{cm}^{3}$, can indicate an enhanced defectness of grain boundaries in these magnets, which can in turn be related to the strong deterioration of the vacuum upon the heating of wet powders because of the intense release of toluene vapors.

\section{Effect of Size of Powder Particles on Properties of Sintered Magnets}

Figure 5 displays the dependence of the average size of powder particles on the milling time $t_{\mathrm{mil}}$ in the vibrating mill. Upon the introduction of $0.15 \mathrm{wt} \%$ zinc stearate, $D_{\text {av }}$ decreases more rapidly as compared 
(a)

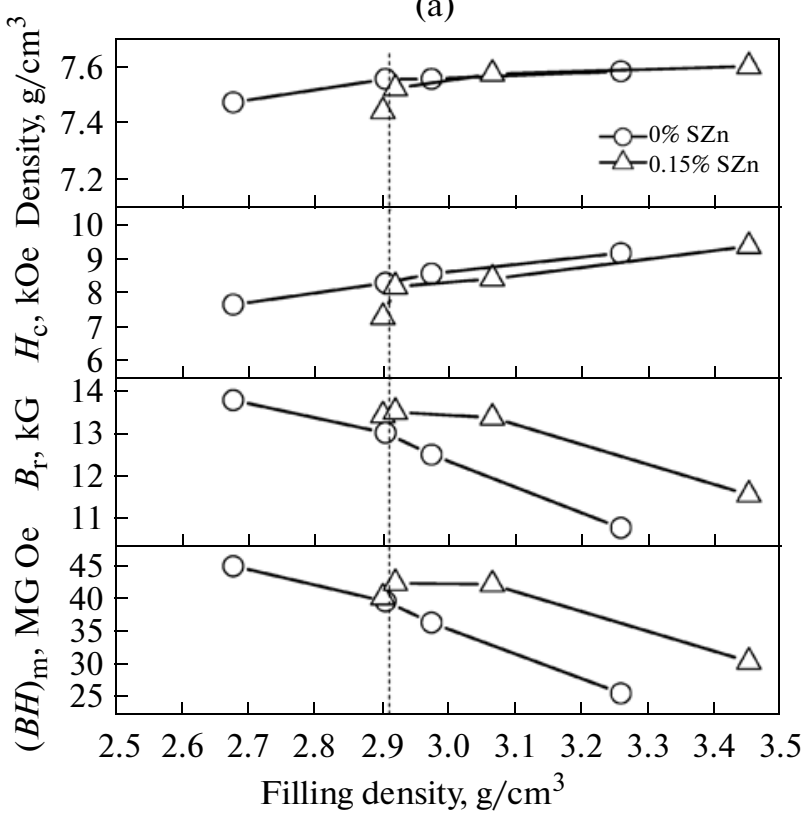

(b)

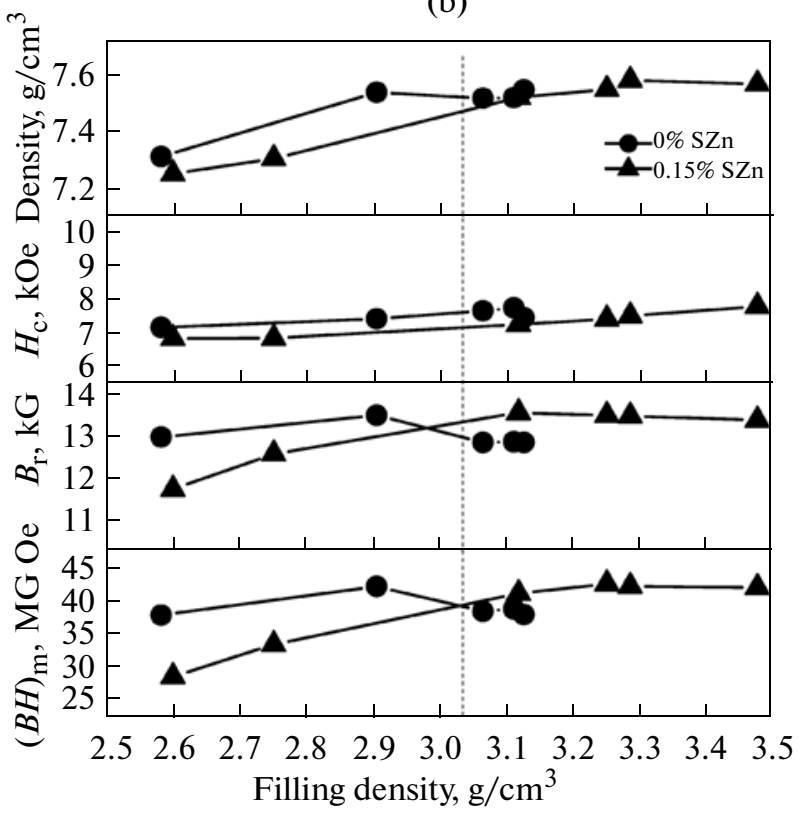

Fig. 4. Effect of (a) dry and (b) wet powders loaded into containers onto properties of sintered magnets.

to $D_{\text {av }}$ of the powders prepared without zinc stearate. This result suggests that, in milling, zinc stearate acts as a surfactant. Figure 6 displays micrographs of powders milled in the presence of zinc stearate. It can be seen that, along with a decrease in $D_{\text {av }}$, an increase is observed in the fraction of fine particles, and the particles become more rounded. Qualitatively similar micrographs were obtained for the powders prepared without zinc stearate.

The sintered magnets were produced from wet powders milled both with and without the addition of $0.15 \mathrm{wt} \%$ zinc stearate. The dependences of the filling density of powders and the properties of sintered magnets on the average size of particles are shown in Fig. 7. The values of $\rho_{\mathrm{f}}$ decrease gradually with decreasing $D_{\text {av }}$. For wet powders milled with an addition in zinc stearate, just as in the case of dry powders, the values of $\rho_{\mathrm{f}}$ (under identical conditions of loading) prove to be higher compared to powders prepared without zinc stearate. The tendency of the density of sintered magnets to decrease, which is usually observed with increasing $\rho_{\mathrm{f}}$, is compensated for in the obtained dependences by an increase in the sinterability of fine particles; in the range of $D_{\mathrm{av}}=2.7-3.2 \mu \mathrm{m}$, the values of $\rho$ remain almost constant and are no less than $7.54 \mathrm{~g} / \mathrm{cm}^{3}$. A sharp decrease in density was found in the magnet prepared from the powder with the addition of zinc stearate with an average particle size of $2.55 \mu \mathrm{m}$. The main factor responsible for this decrease appears to be the excessive oxidation of the intergrain $\mathrm{Nd}$-rich phase.

Dependences that are qualitatively similar to $\rho\left(D_{\mathrm{av}}\right)$ have also been obtained for $B_{\mathrm{r}}\left(D_{\mathrm{av}}\right)$. Further- more, there is some increase in $B_{\mathrm{r}}$ with decreasing $D_{\mathrm{av}}$. This increase is due to the improvement of the degree of texture, which clearly follows from the X-ray diffraction patterns shown in Fig. 8 taken from the surface of sintered magnets perpendicular to the direction of the texture. In the X-ray diffraction pattern (Fig. 8a) of the magnet prepared from a powder with $D_{\mathrm{av}}=$ $3.2 \mu \mathrm{m}$ without zinc stearate, the intensity of the (105) line exceeds that of the (006) line, which indicates the insufficiently sharp texture [9] of this magnet. A decrease in the average size of particles to $2.6 \mu \mathrm{m}$ led

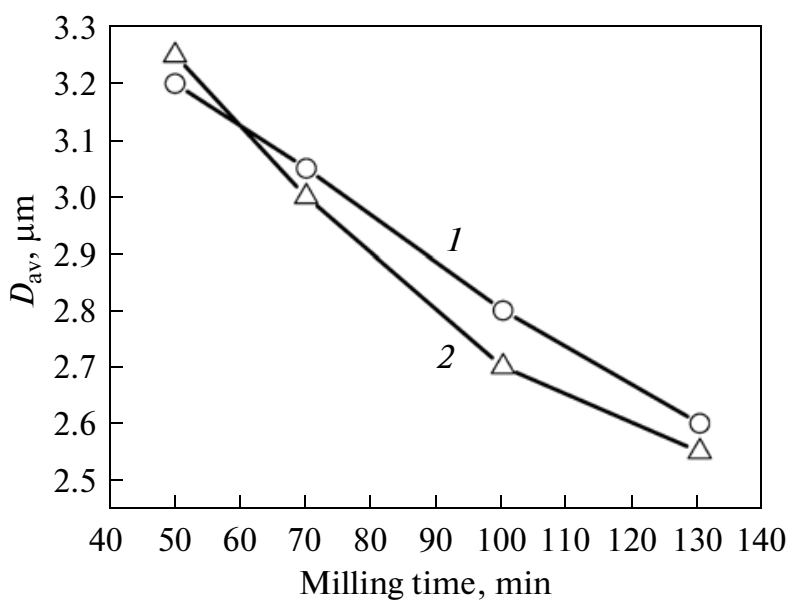

Fig. 5. Dependence of average particle size of powders prepared (1) without and (2) with addition of $0.15 \mathrm{wt} \%$ zinc stearate on the time $t_{\text {mil }}$ of milling in a vibrating mill. 

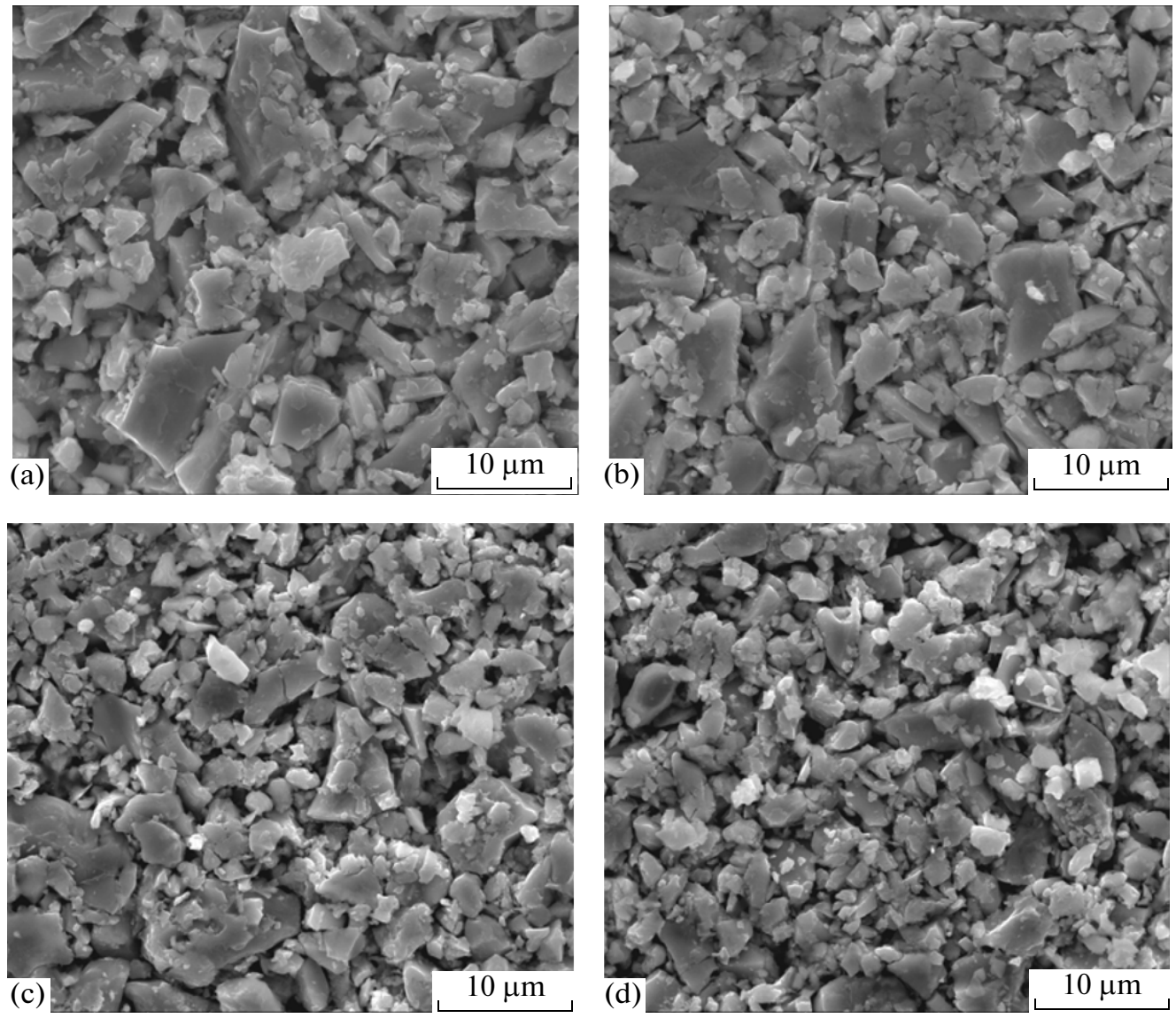

Fig. 6. Micrographs of powders milled with additions of zinc stearate: (a) $D_{\mathrm{av}}=3.25$, (b) 3.00 , (c) 2.70 , and (d) $2.55 \mu \mathrm{m}$.

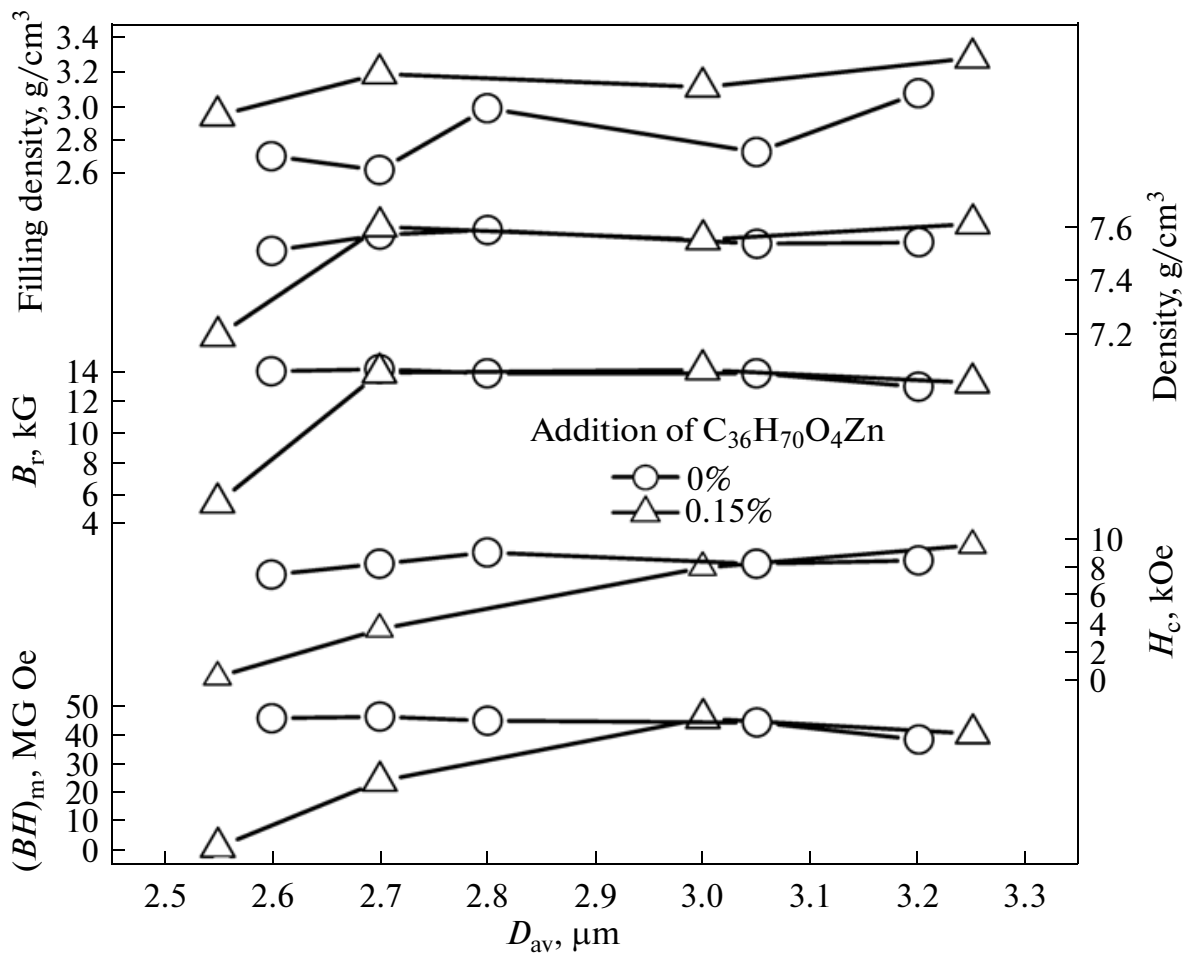

Fig. 7. Density of wet powders charged into containers and properties of sintered magnets as functions of average particle size. 


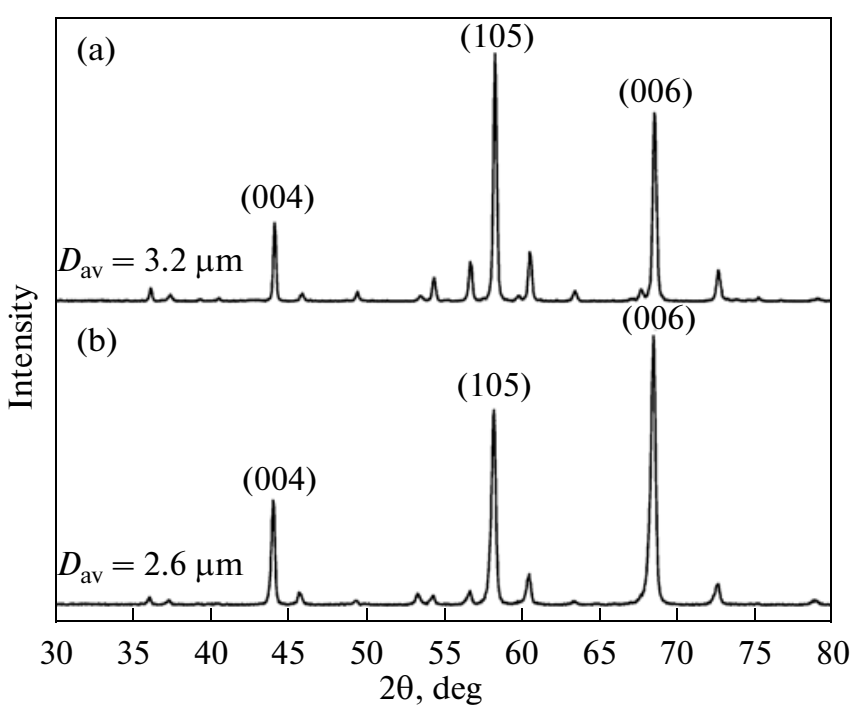

Fig. 8. X-ray diffraction patterns taken from surfaces of sintered magnets perpendicular to direction of texture.

to an increase in $B_{\mathrm{r}}$ of the magnet by $0.9 \mathrm{kG}$; the ratio between the intensities of the (105) and (006) lines in this case became opposite. The improvement in the degree of texture is related to changes (shown in Fig. 6) in the morphology of the powders and the particle-size distribution, which is accompanied by a decrease in the fraction of particles with remainders of dendritic blocks $10-15 \mu \mathrm{m}$ in size, in which the easy axes of the $\mathrm{Nd}_{2} \mathrm{Fe}_{14} \mathrm{~B}$ grains are slightly misoriented [10]. A similar change in the ratio between the intensities of the (105) and (006) lines was also observed for magnets prepared with an addition of zinc stearate; therefore, the sharp decrease in $B_{\mathrm{r}}$ in the magnet pre- pared from a powder with $D_{\mathrm{av}}=2.55 \mu \mathrm{m}$ appears to be due to the decrease in $\rho$ noted above and a very low $H_{c}$, which decreases monotonically in this series of magnets (see Fig. 7), rather than to the deterioration of the texture.

The dependences of the values of the coercive force and oxygen content in sintered magnets on the average particle size of powders that were loaded into containers in a wet state are shown in Fig. 9. A comparison with the data given in Table 3 shows that the use of wet (instead of dry) powders with the same $D_{\mathrm{av}}=3.2 \mu \mathrm{m}$ made it possible to decrease the oxygen content in the magnets by $14 \%$ (to $0.36 \mathrm{wt} \%$ ). As the $D_{\text {av }}$ of the powders decreased to $2.6 \mu \mathrm{m}$, the oxygen content in the magnets prepared without the addition of zinc stearate increased to $0.43 \mathrm{wt} \%$, but their coercive force remained almost unaltered. Note that, in the traditional technology [4], the application of dry powders with $D_{\mathrm{av}}<3.2 \mu \mathrm{m}$ was accompanied by a sharp decrease in $H_{\mathrm{c}}$, though the initial alloy contained a greater (by $1 \mathrm{wt} \%$ ) amount of neodymium compared to the alloy employed in this work.

The reduction of $D_{\mathrm{av}}$ by milling powders with additions of $0.15 \mathrm{wt} \%$ zinc stearate led to a monotonic decrease in $H_{\mathrm{c}}$ of the sintered magnets and, simultaneously, to a substantial increase in the oxygen content in them. The rate of heating of the powders in a vacuum before sintering proved to be too high, which did not favor the complete removal of zinc stearate from the surface of particles. The magnets with fairly high properties $\left(\rho=7.55 \mathrm{~g} / \mathrm{cm}^{3}, B_{\mathrm{r}}=14.02 \mathrm{kG}, H_{\mathrm{c}}=\right.$ $7.91 \mathrm{kOe}$ and $(B H)_{\max }=46.1 \mathrm{MG}$ Oe) were only obtained from a powder with $D_{\text {av }}=3.0 \mu \mathrm{m}$. To obtain a higher level of properties, additional investigations are required to find an optimum regime of the removal of zinc stearate.

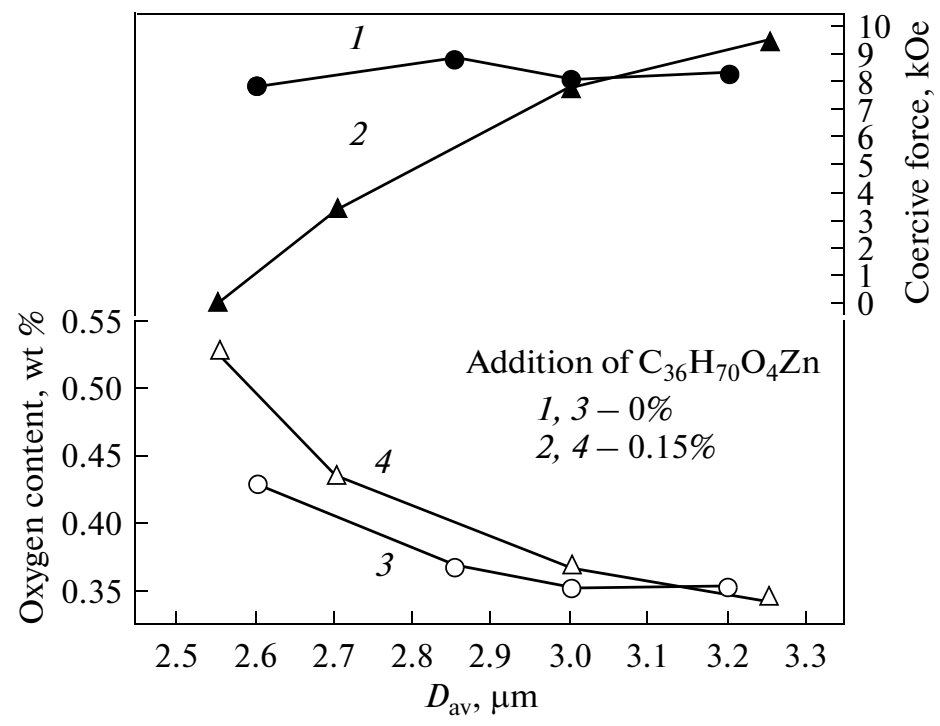

Fig. 9. Dependences of values of coercive force and oxygen content in sintered magnets on average particle size of powders loaded into containers in a wet state. 


\section{CONCLUSIONS}

(1) The use of additions of zinc stearate in the course of milling of the $\mathrm{Nd}-\mathrm{Fe}-\mathrm{B}$ alloys in a toluene medium made it possible to increase the degree of texture induced by a magnetic field in powders. The increment in the degree of texture proves to be more substantial when using an enhanced filling density of the powder $\left(\rho_{\mathrm{f}} \geq 3 \mathrm{~g} / \mathrm{cm}^{3}\right)$.

(2) Zinc stearate added during the milling of powders acts as a surfactant and favors an increase in the filling density of powders upon loading them into containers under identical conditions of compacting.

(3) The use of wet powders instead of dry permitted us to decrease the oxygen concentration in the sintered magnets by $14 \%$.

(4) The density and magnetic hysteresis characteristics of sintered magnets prepared with an addition of $0.15 \mathrm{wt} \%$ zinc stearate exceed the corresponding values for magnets prepared without additions at filling densities more than 2.9 and $3.0 \mathrm{~g} / \mathrm{cm}^{3}$ in the dry and wet states, respectively.

(5) Using a zinc stearate addition of $0.15 \mathrm{wt} \%$, magnets with the following properties were prepared from a wet powder with an average size of particles equal to $3.0 \mu \mathrm{m}$ and density of loading into the containers equal to $3.11 \mathrm{~g} / \mathrm{cm}^{3}$ without subsequent pressing as follows: $\rho=7.55 \mathrm{~g} / \mathrm{cm}^{3}, B_{\mathrm{r}}=14.02 \mathrm{kG}, H_{\mathrm{c}}=$ $7.91 \mathrm{kOe}$, and $(B H)_{\max }=46.1 \mathrm{MG}$ Oe.

\section{ACKNOWLEDGMENTS}

This work was supported in part by the Russian Academy of Sciences, Ural Branch (project no.12-M23-2066). For the experiments, the equipment of the Ural-M Center of Collaborative Access was used. We are grateful to N.V. Nikolaeva for the investigation of the morphology of powders at the Center of Collaborative Access of the Department of Electron Microscopy, Institute of Metal Physics, Ural Branch, Russian Academy of Sciences, and to A.V. Shitov for measurements of the average size of powder particles.

\section{REFERENCES}

1. M. Sagawa and Y. Une, "A New Process for Producing $\mathrm{Nd}-\mathrm{Fe}-\mathrm{B}$ Sintered Magnets with Small Grain Size," Proc. 20th Int. Workshop on Rare Earth Permanent Magnets and Their Applications (Knossos-Crete, 2008), pp. 103-105.

2. W. F. Li, T. Ohkubo, K. Hono, and M. Sagawa, "The Origin of Coercivity Decrease in Fine Grained Nd$\mathrm{Fe}-\mathrm{B}$ Sintered Magnets,” J. Magn. Magn. Mater. 321, 1100-1105 (2009).

3. M. Sagawa, "Development and Prospect of the Nd$\mathrm{Fe}-\mathrm{B}$ Sintered Magnets," Proc. 21st Int. Workshop on Rare-Earth Permanent Magnets and Their Applications (Bled, Slovenia, 2010), pp. 183-186.

4. A. G. Popov, A. V. Shitov, E. G. Gerasimov, D. Yu. Vasilenko, M. Yu. Govorkov, D. Yu. Bratushev, V. P. Vyatkin, K. Yu. Shunyaev, and T. L. Mikhailova, "Preparation of Sintered Nd-Fe-B Magnets by Pressless Process," Phys. Met. Metallogr. 113, 331-340 (2012).

5. Yu. Kaneko, RF Patent No. 2112627.

6. P. K. Gaschl, RF Patent No. 2258345.

7. A. G. Popov, T. Z. Puzanova, V. S. Gaviko, D. Yu. Vasilenko, and V. P. Vyatkin, "Formation of a High-Coercive State in Sintered Nd-Fe-B-Ga Magnets by Thermocycling," Phys. Met. Metallogr. 101, 538-546 (2006).

8. W. Rodewald, R. Blank, B. Wall, G. W. Reppel, and H. D. Zilg, "Production of Sintered Nd-Fe-B Magnets with Maximum Energy Density of 53 MG Oe," Proc. 16th Int. Workshop on Rare-Earth Permanent Magnets and Their Applications (Sendai, Japan, 2000), pp. 119-126.

9. M. Endoh and M. Shindo, "Material Design and Fabrication of High Energy Nd-Fe-B Sintered Magnets," Proc. 13th Int. Workshop on Rare-Earth Permanent Magnets and Their Applications (Birmingham, United Kingdom, 1994), pp. 379-404.

10. A. G. Popov, N. V. Kudrevatykh, V. P. Vyatkin, D. Yu. Vasilenko, D. Yu. Bratushev, T. Z. Puzanova, and E. G. Gerasimov, "Preparation of High-Power Permanent Magnets from Platelike $\mathrm{Nd}-\mathrm{Fe}-\mathrm{B}$ Alloys," Phys. Met. Metallogr. 109, 238-246 (2010). 